\title{
CURANDEIRISMO, CURANDEIRICES, PRÁTICAS \\ E SABERES TERAPÊUTICOS: REFLEXÕES SOBRE \\ O PODER MÉDICO NO BRASIL
}

\author{
HEALER, FAITH HEALING, THERAPEUTIC PRATICS \\ AND KNOWLEDGE: REFLECTIONS ONTHE \\ MEDICAL POWER IN BRAZIL
}

Rodolfo Franco Puttini(*)

\section{RESUMO}

O objetivo deste trabalho é recuperar os recursos discursivos disponíveis sobre o tema curandeirismo gerados pelo campo jurídico, tendo em vista refletir sobre o lugar das curandeirices e práticas e saberes terapêuticos no campo da saúde. Analiso diferentes depoimentos em um julgamento do crime de curandeirismo sobre os quais depreendo elementos fundamentais para análise arqueológica do poder médico no Brasil.

\section{Palavras-chave}

Curandeirismo; Medicina Tradicional; Saúde.

\section{ABSTRACT}

The objective of this work is to recover the discursive resources available on the subject of healer generated by the juridic field, em view to reflect on the place of faith healing, therapeutic knowledges and therapeutic practice in

(*) Cientista Social, doutor em Saúde Coletiva pela Universidade Estadual de Campinas (UNICAMP), professor assistente no Departamento de Saúde Pública, Faculdade de Medicina de Botucatu, Universidade Estadual Paulista "Júlio Mesquita Filho" (UNESP). Botucatu/SP-Brasil. E-mail: <puttini@fmb.unesp.br>. Recebido em 30.03.09. Revisado em 08.10.09. Aprovado em 12.07.10. 
the health field. Analyze different statements in a trial of the crime of healer on which I understand the key elements for archaeological analysis of medical power in Brazil.

\section{Keywords}

Faith Healing; Health; Traditional Medicine

\section{INTRODUÇÃO: O CONCEITO DE CURANDEIRISMO}

Desde a Proclamação da República no Brasil, e de modo bastante peculiar $^{(1)}$, o Estado brasileiro dispensa tratamento legal às práticas de cura por meio de legislação específica, caracterizando-as por ações criminosas relativas à saúde pública. Com o tempo, estabeleceu-se uma jurisprudência exclusiva sobre $o$ assunto ${ }^{(2)}$, que traduz as normas e condutas sociais para as variadas formas de curandeirices no país, sintetizadas no conceito curandeirismo ${ }^{(3)}$.

De fato, é corrente entre profissionais de saúde que o termo curanderismo sintetiza uma ação criminosa e representa as curandeirices populares, identificadas por práticas ultrapassadas desde a origem da medicina científica. Por exemplo, Haring ${ }^{(4)}$ relaciona o curandeirismo com o sentido da ética médica, define-o por atitudes de comportamento de uma cultura ou grupo profissional que assumem uma hierarquia de valores e se o código ético é o "esforço de alimentar e garantir o ethos" a moralidade médica consiste na realização do ethos. Para Campos, ${ }^{(5)}$ importa associar à deontologia (ciência do dever): o curandeirismo e o charlatanismo são conceituados como um crime à saúde pública, uma vez que para ele escapa da conduta "inculcando ou anunciando a cura por meio secreto e infalível". León $n^{(6)}$ identificou curandeirismo a "charlatanismo" pela classificação das práticas heréticas em

(1) PEIXOTO, I. D. Superstição e crime no Brasil. São Paulo: Ed. Revista dos Tribunais, 1980.

(2) SCHRITZMEYER, A. L. P. Sortilégio de saberes: curandeiros e juízes nos tribunais brasileiros (1900-1990). São Paulo: IBCCrim, 2004.

(3) Os artigos penais relativos à prática médica, prescritos no Código Penal desde sua primeira versão em 1890 e subsequentes modificações (1930, 1945). Atualmente em vigor, são os seguintes três artigos penais relativos às práticas não médicas: "Exercício llegal da Medicina: exercer, ainda que a título gratuito, a profissão de médico, dentista ou farmacêutico, sem autorização legal ou excedendo-Ihe os limites"; "Charlatanismo: inculcar ou anunciar cura por meio secreto infalível; e "Curandeirismo ou exercer o curandeirismo: I. prescrevendo, ministrando ou aplicando, habitualmente, qualquer substância; II. usando gestos ou qualquer outro meio; III. fazendo diagnósticos".

(4) HARING, B. Medicina e moral no século XX. Rio de Janeiro: Ed. Verbo, 1974.

(5) CAMPOS, J. Q. O hospital, a lei e a ética. São Paulo: São Paulo Ed., 1976.

(6) LÉON, A. C. Ética en medicina. Barcelona: Ed. Científico-Médica, 1973. 
relação à medicina oficial: naturopatas, quiropatas, acumputuristas, homeopatas: "são práticas que se baseiam em teorias rígidas da doença, sem base científca, suscetíveis de serem submetidas à comprovação, enquanto a medicina científica dispõe de conhecimentos conduzidos de forma racional e metódica." De modo geral, o conceito releva que práticas curandeiras são revistas como desviantes e o sistema jurídico é o local adequado para resolver esses problemas persistentes de saúde causados por agentes curandeiros.

Neste ensaio, pretendo mostrar que o conceito jurídico de curandeirismo manifesta-se como um problema social para o campo da Saúde Coletiva. Em princípio, o tema se identifica com o conceito e definição das "medicinas tradicionais", estabelecida pela Organização Mundial de Saúde (OMS) como: "sistemas de medicina baseados em crenças culturais e práticas passadas de geração a geração, (conceito que) inclui rituais místicos e mágicos (terapias espirituais), fitoterapia e outros tratamentos que podem não ser esclarecidos pela medicina atual." ${ }^{\prime(7)}$

Por outro lado, nas décadas de 1980-90 cientistas sociais pretenderam abolir essas amarras conceituais, distinguindo no nível local os sentidos de curandeirismo, próprios da realidade social brasileira. O clássico trabalho de Loyola(8). pioneiro na época, retratou na vida social do bairro de Santa Rita do Rio de Janeiro as diversas práticas de cura convivendo no cenário urbano de modo consensual com a prática médica. O estudo de Machado et. al. ${ }^{(9)}$ também modelou uma alternativa histórica para descrever as medicinas tradicionais no contexto genealógico do poder no Brasil colonial. Mais atualmente, esse duplo sentido - ora significando o curandeirismo uma ação criminosa, ora uma atividade terapêutica — ficou estabelecido em meu trabalho de tese ${ }^{(10)}$ como limiar entre a medicina tradicional e a medicina oficial pela conformação do habitus científico, estruturado em nossa sociedade entre a prática médica e a prática religiosa.

O objetivo deste trabalho será de recuperar os recursos discursivos disponíveis sobre o tema curandeirismo gerados pelo campo jurídico, tendo em vista a finalidade de refletir sobre o lugar das curandeirices e práticas e saberes terapêuticos no campo da saúde ${ }^{(11)}$. Especificamente seguirei a seguinte hipótese de trabalho: diante da atual circunstância - em que se

(7) Confrontar o verbete "medicina tradicional" em Descritores em Ciências da Saúde (DEcs).

(8) LOYOLA, M. A. Médicos e curandeiros: conflito social e saúde. Rio de Janeiro: Difel, 1984.

(9) MACHADO, R.; Loureiro, A.; Luz, R.; MURICY, K. Danação da norma: medicina social e constituição da psiquiatria no Brasil. Rio de Janeiro: Graal, 1978.

(10) PUTTINI, Rodolfo Franco. Curandeirismo e o campo da saúde no Brasil. Interface, Botucatu, v. 12, n. 24, mar. 2008.

(11) ALMEIDA FILHO, N. For a general theory of health: preliminary epistemological and anthropological notes. Cadernos de Saúde Pública, Rio de Janeiro, v. 17, n. 4, p. 753-770, 2001. 
implementou oficialmente no Sistema Único de Saúde (SUS) as práticas de saúde complementares e integrativas ${ }^{(12)}$, como a homeopatia e acupuntura(13), inclusive reconhecidas pelo Conselho Federal de Medicina enquanto práticas terapêuticas medicas - ${ }^{(14)}$, o conceito de curandeirismo, gerado pelo discurso médico e reproduzido no campo jurídico, aparece como um termo de interface ideológica, que representa os conflitos de legitimidade dos saberes populares e curandeirices em geral ${ }^{(15)}$.

Nesse contexto, propus, em projeto de pesquisa, o exame dos enunciados médicos em um julgamento do crime de curandeirismo, ocorrido na decada de 1980 em Campinas. Da análise dos relatos segui com reflexões sobre o campo da saúde, partindo da discussão sobre as fronteiras das práticas curandeiras diante da medicina hegemônica. Adotei por metodologia a referência teórica da arqueológica do saber elaborada por Michel Foucault. Utilizei o caminho da análise do discurso, assim definida pelo autor:

A análise do campo discursivo é orientada de forma inteiramente diferente; trata-se de compreender o enunciado na estreiteza e singularidade de sua situação; de determinar as condições de sua existência, de fixar seus limites da forma mais justa, de estabelecer suas correlações com outros enunciados a que pode estar ligado, de mostrar que outras formas de enunciação exclui. Não se busca, sob o que está manifesto, a conversa semi-silenciosa de um outro discurso: deve-se mostrar por que não poderia ser outro, como exclui qualquer outro, como ocupa, no meio dos outros e relacionado a eles, um lugar que nenhum outro poderia ocupar. A questão pertinente a uma tal análise poderia ser assim formulada: que singular existência é esta que vem à tona no que se diz e em nenhuma outra parte ${ }^{(16)}$

Michel Foucault compreende a unidade do discurso e sua regularidade enunciativa por meio dos acontecimentos descritos por fatos dos discursos enquanto jogos de relações (op. cit., p. 23-35). Para o filósofo as práticas jurídicas formalizam a principal fonte dos discursos:

(12) LUZ, M. Racionalidades médicas e terapêuticas alternativas. Rio de Janeiro: UERJ/IMS, 1993; POLÍTICA NACIONAL DE PRÁTICAS INTEGRATIVAS E COMPLEMENTARES NO SUS - PNPIC-SUS. Departamento de Atenção Básica, Secretaria de Atenção à Saúde, Ministério da Saúde. Brasília: Ministério da Saúde; 2006; BARROS, Nelson Filice de; NUNES, Everardo Duarte. Complementary and alternative medicine in Brazil: one concept, different meanings. Cadernos de Saúde Pública, Rio de Janeiro, v. 22, n. 10, out. 2006.

(13) LAUCAS, C. R.; LUZ, M. A estrutura do campo médico homeopático do Rio de Janeiro: reflexões sobre a produção do conhecimento como elemento básico de estruturação institucional sistêmica do campo. Estudos de Saúde Coletiva, n. 178, p. 3-29, 1998.

(14) ROSENBAUM, P. Homeopatia: medicina interativa, história lógica da arte de cuidar. Rio de Janeiro: Imago, 2002.

(15) QUEIROZ, M. S. Representações sobre saúde e doença: agentes de cura e pacientes no contexto do SUDS. Campinas: Ed. da Unicamp, 1991.

(16) FOUCAULT, M. A arqueologia do saber. 3. ed. Rio de Janeiro: Forense Universitária, 1987. p. 31-32. 
(...) entre as práticas sociais em que a análise histórica permite localizar a emergência de novas formas de subjetividades, as práticas jurídicas, ou mais precisamente, as práticas judiciárias estão entre as mais importantes. (...) As práticas judiciárias me parecem uma das formas pelas quais nossa sociedade (ocidental) definiu tipos de subjeividade, formas de saber e, por conseguinte, relações entre o homem e a verdade que merecem ser estudadas. ${ }^{(17)}$

\section{OS ARGUMENTOS SOBRE CURANDEIRISMO NO CAMPO JURÍDICO}

Algumas precauções foram tomadas para o desenvolvimento do projeto de pesquisa ${ }^{(18)}$. Solicitei inicialmente autorização junto ao cartório do Fórum de Campinas para acesso aos arquivos judiciais. Selecionei um processo judicial, cujo réu deveria ter sido acusado, julgado e condenado pelo crime de curandeirismo na década de $1980^{(19)}$. De posse do material, procedi à análise dos discursos médicos. Faço em seguida uma apresentação do caso.

Estavam no jogo sete pastores protestantes acusados do crime de curandeirismo diante de um episódio que envolvia um de seus fiéis ${ }^{(20)}$. V. R. sentia dores em sua perna esquerda, quando procurou ajuda em um hospital, onde foi submetido a uma pequena cirurgia. No entanto, antes do término da internação fugiu, quando teria ouvido em sua casa, em uma propaganda de rádio, que haviam pessoas sendo curadas por pastores religiosos no centro da cidade de Campinas. Procurou, então, ajuda dos agentes religiosos em sua sede e de lá intervieram ungindo com óleo e água benta em sua perna, pedindo-Ihe que retornasse por nove semanas para manter o mesmo procedimento religioso. O fiel, no entanto, interrompeu o tratamento na casa religiosa na terceira semana quando, a pedido dos dirigentes, retornou a outro hospital para retirar aqueles pontos cirúrgicos que ainda permaneciam desde a primeira operação médica, motivo pelo qual as dores se intensificaram. No segundo espaço hospitalar, criou-se um impasse porque os médicos queriam, antes do paciente se ausentar do local, amputar sua perna. Porém,

(17) FOUCAULT, M. As verdades e formas jurídicas: conferências de Michel Foucault na PUC-Rio de 21 a 25 de maio de 1973. Rio de Janeiro: Nau Ed., 1999. p. 11.

(18) PUTTINI, Rodolfo Franco. O poder médico e sua relação com outras práticas de cura. Campinas: Departamento de Medicina Preventiva e Social, Unicamp, 1989. [Relatório de Pesquisa].

(19) Utilizei os seguintes critérios para a seleção dos processos judiciais a serem estudados: a) processos que teriam sido concluídos e julgados pelo poder judiciário; b) processos que teriam sido punidos com sanções previstas pelo Código Penal; c) escolha de no máximo três processos dentre os quais estivessem concluídos entre os anos de 1980 e 1985.

(20) Será mantido no anonimato os atores-personagens do processo judicial, indicando-se abreviaturas do nome. 
ele e sua mãe desejavam voltar ao templo religioso para obter a cura sem a perda do membro enfermo. Os médicos chamaram a polícia e esses interviram fazendo com que o paciente assinasse uma declaração de consentimento para efetivar qualquer tratamento médico. Assim, a perna foi amputada e o delegado de polícia iniciou inquérito policial encaminhando um relatório final ao promotor público da cidade que acusou os pastores religiosos do crime de curandeirismo, inclusos no art. 284 do Código Penal.

O conteúdo principal dos discursos se repete no processo criminal de curandeirismo, como em um quebra-cabeça em montagem. Depoimentos diversos esforçam-se por manter o sentido dos fatos, reconstituindo detalhes que asseguram uma argumentação ponderada entre aspectos positivos e negativos da ação criminosa, como prescrito na lei.

Por exemplo, nos autos do processo judicial constavam duas declarações médicas: da equipe que estava no hospital no dia da amputação e da equipe médico-legista, que emitiu um laudo sobre o caso. A equipe médica do hospital declarou sobre o exame do paciente, indicando a urgência e o perigo com a vida da vítima: “... apresenta o membro inferior esquerdo inviável sendo indicada internação para tratamento hospitalar e investigações clínicas, em regime de urgência com risco de vida." (Declaração da equipe médica local.)

Essa declaração ainda informava que "após esclarecimentos prestados ao delegado de polícia, o paciente concordou com qualquer tratamento a ser proposto pela equipe médica que irá tratar do caso" (depoimento da equipe médico-legista). Entretanto, o delegado de polícia pediu maiores orientações ao Departamento de Polícia Científica no mesmo dia da ocorrência dos fatos. Os médicos-legistas fizeram o exame de corpo delito antes dos depoimentos dos pastores. Depois de examinado, a equipe médica respondeu com um parecer final sobre o problema central, que se resumiu na seguinte questão: “... criou-se o problema: o médico (local) pode ou não intervir mesmo contra a vontade do paciente?" Justificaram depois a intervenção referindo-se ao fiel enquanto um paciente sob dois aspectos: o seu estado cultural e o estado físico. O primeiro aspecto verificou-se com relação aos pseudopastores: Trata-se de uma pessoa de baixo nível cultural e material (indigente), sendo dessa forma uma presa fácil para o culto destes pseudos pastores, pastores que em última análise são na verdade 'curandeiros'." (21)

O médico-legista, por sua vez, relatou sobre o estado físico da vítima, uma pessoa desnutrida e abatida pela doença em sua perna. Estava com o pé esquerdo em gangrena e explicou o significado de gangrena detalhando o processo de evolução da necrose em seu pé, que já se encontrava mimificado:

(21) Declaração do médico local. 
A gangrena significa necrose em massa de uma parte cuja cor e consistência são modificados por agentes externos, como o ar e bactérias. Ela pode ser seca ou úmida. A parte necrótica torna-se negra por alteração da hemoglobina e seca por perda de água, adquirindo aspecto de múmia. Pode proceder a cor negra a vermelho-azulada, indicadora de distúrbios circulatórios, mas ainda não de necrose.(22)

Respaldados no código de ética médica apontando o capítulo da responsabilidade médica, os médicos locais averiguaram a conduta de intervenção na circunstância de haver "perigo iminente de vida do paciente". Pois "obrigação para os médicos de sofrer as consequências de faltas por eles cometidos no exercício da arte, faltas que poderiam originar uma dupla ação civil e penal" (depoimento do médico local). Ou seja, segundo essa interpretação, após o exame, o médico ter constatado a gravidade do caso e permitir que o paciente, conforme sua vontade, evadisse do espaço hospitalar, estaria o médico incorrendo em omissão de socorro (art. 146 do Código Penal). Dessa forma, a equipe médico-legal justificou os procedimentos e concluiu que "a única solução para o problema, única atitude humana e médica no presente caso é a amputação do membro doente" (Declaração da equipe médico-legista).

Por outro lado, os sete pastores religiosos envolvidos no caso foram ouvidos na delegacia de polícia. Tentaram provar em vão que os acontecimentos não se relacionavam com a prática do curanderismo. Ao contrário, os pastores buscaram justificativas na questão da fé, cujo conhecimento teológico está dado na Bíblia, que orienta os fiéis nas questões de saúde. Explicou sobre o trabalho caritativo, que consistia em pregar o evangelho proferindo-se sermões no templo, três vezes ao dia. Os fiéis quando convertidos passariam a seguir a crença e seriam nomeados membros da igreja, colaboradores de dízimos. Ao se referir à vítima do curandeirismo, um dos pastores contou que esteve com seus familiares, e que esses the pediram a cura para a perna doente. Compreendeu, depois de receber informações dos familiares a respeito do atendimento médico, que após cirurgia os médicos "haviam desenganado o paciente". O líder espiritual orientou procurar novamente o hospital, mas os familiares da vítima disseram-lhe que não iriam proceder dessa forma porque já haviam insistido nesse aspecto.

Diante disso, aconselhou "pedir a cura de Deus por meio da oração". O pastor compreendeu ainda que sua função limitava-se a corresponder com aqueles que os procuravam e alertando sobre suas intenções acrescentou: "doutrinamos a ter fé no evangelho, não prescrevendo medicamentos e nem fazendo passes ou coisas parecidas." Disse, enfim, não ter tocado no paciente e a esse respeito, esclareceu o mal-entendido ao escrivão de polícia:

(22) Declaração do médico local. 
... aconselhou pedir a cura de Deus através da oração, mas não tocou no doente e os familiares do doente nada pagaram por isso ... esclarece ainda que usa óleo e água benta para ungir as pessoas, segundo o que é preconizado pela Bíblia. (Depoimento do agente religioso).

No debate jurídico, o promotor público pronunciou a denúncia a todos os religiosos incursos na disposição penal do curandeirismo. Relatou os fatos pela versão disponível nos autos e entendeu que utilizaram gestos e palavras, prescreveram e ministraram óleo e água benta, de acordo com o que está prescrito na lei. Fundamentou sua tese apresentando argumentos acerca dos fatos ocorridos no templo religioso e no hospital, o primeiro procurado por diversas pessoas, que eram persuadidas a praticarem processos de cura e onde a vítima foi atendida pelo pastor, prometendo curá-lo e retirar a obra de macumba que havia em sua perna. O promotor, identificando a vítima, acrescentou algumas possíveis provas dos responsáveis: tinham o propósito de "realizar curas em pessoas humildes embora não tivessem habilitação" exigida e faziam propaganda das curas que realizavam, solicitando contribuições em dinheiro para a entidade religiosa.

$\mathrm{O}$ advogado de defesa por sua vez declarou-se inconformado com a tipificação dos acusados ao crime e se habilitou provar que não estava totalmente justificada a violação à lei penal. Esclareceu sobre os princípios daquela religião e argumentou sobre o indevido enquadramento dos acusados às características de curandeiros e, por anulação, identificou-os como "ministros evangélicos de convicção religiosa ou missionários evangélicos" que, devidamente institucionalizados e legalizados pela organização do templo, eram ordenados profissionais para o "exercício de pregação do evangelho de Jesus". Alegou não ser a promessa de cura em nome de Jesus Cristo um crime uma vez que, como demonstrou o ofício legal dos pastores, obedecem às ordens do próprio Jesus. Citou os preceitos nas escrituras bíblicas dos seguintes dizeres:

.... ide por todo mundo e pregai o evangelho a toda a criatura. Quem crê e for batizado será salvo, mas quem não crê será condenado e estes sinais seguirão aos que crerem em meu nome expulsarão os demônios, falarão novas línguas e pegarão nas serpentes; e se beberem alguma coisa mortífera não lhes fará dano algum e porão as mãos sobre os enfermos e os curarão - Bíblia, S. Marcos, cap. 16. ${ }^{(23)}$

$\mathrm{O}$ juiz de direito relatou o caso do que percebeu dos autos e decidiu a sentença condenatória dos acusados-réus a seis meses de detenção. Para chegar a essa decisão, interpretou que os acusados afirmaram a tese da acusação apesar de ao deporem "procurando dar aos fatos colorido diverso do que ali consta sob o rótulo de curandeirismo". Colocando em contraste os

(23) Declaração do advogado de defesa. 
argumentos dos advogados de defesa e advogados promotores, o juiz acentuou a prática dos agentes religiosos enquanto os maiores implicados no caso: disseram que suas atividades atestavam circunscrever ao fato de pregação bíblica e asseveraram que não houve cobranças em dinheiro, mas as pessoas se dispuseram ao pagamento de dízimos. A unção com óleo igualmente foi justificada religiosamente, pois a Bíblia pregava que Jesus assim curava as pessoas. Conforme a fundamentação de seu discurso, o juiz visualizou a abstração em que se encontrava a tese da defesa (liberdade de culto religioso), ao confrontar com o prescrito em lei sobre o crime do curandeirismo e citando um influente jurisprudente argumentou as provas do crime:

Caracteriza curandeirismo o tratamento de mazelas físicas ou psíquicas, mediante passes, benzeduras, "operações espirituais", etc. - por se inculcar intermediário para benéfica atuação das forças do além. Quem assim procede transgride a lei penal, mesmo que não prescreva, administre ou aplique qualquer substância com fins curativos, nem receba remuneração dos que, crédulos, ou desesperados, para a "cura" de seus males o procuram" (RT 374); "É indispensável ao reconhecimento da prática do curandeirismo a existência de habitualidade por parte do agente. Assim, inexiste o delito no exercício de um ato isolado, ou mesmo alguns (RT 462). ${ }^{(24)}$

Esclareceu, enfim, que as provas do crime estavam inclusas no uso de outro meio, ungindo pessoas de forma habitual. Acrescentou ser um crime de perigo e não de dano, de perigo abstrato e não perigo concreto, isto é, estabeleceu-se o fato criminoso para um número indeterminado de pessoas. Ao fato de aplicar qualquer substância (óleo para ungir as pessoas), o juiz de direito entendeu que houve tipicidade do crime, pois:

há tutela penal estabelecida no sentido de combater a subtração que o curandeirismo venha provocar, visando retirar, afastar as pessoas da medicina convencional, retirá-lo do campo de atuação do médico legalmente habilitado para a prática da medicina. ${ }^{(25)}$

\section{DISCUSSÃO: A FORMAÇÃO DISCURSIVA DO CURANDEIRISMO E DAS CURANDEIRICES EM GERAL}

Vimos em destaque o consenso, nos depoimentos em geral, e dos médicos em particular, em relação ao argumento central que atribui e identifica o agente religioso ao paciente-vítima: ignorância. Esse termo reflete uma imagem, que parece representar um diagnóstico social preconceituoso, e

(24) Declaração do juiz para sentença final.

(25) Depoimento do juiz de direito na sentença final. 
que sugere a principal caracterização do agente de cura em geral atuante fora dos espaços terapêuticos oficiais. Minha hipótese é que essa imagem é reproduzida pelos atores no palco jurídico ${ }^{(26)}$. Provarei, diante dessa hipótese, que o discurso sobre curandeirismo nos depoimentos do processo judicial em questão, segue regras internas ao campo judiciário. Para tanto, proponho resgatar os recursos discursivos propensos em duas direções: a) voltados ao campo jurídico, quando discorrem características gerais do agente curandeiro; b) voltados ao campo da saúde, quando desenvolve a definição do curandeirismo, identificado por um crime bem caracterizado.

\section{O discurso médico do curandeirismo voltado ao campo jurídico}

A equipe médica, que participou da amputação da perna de V. R., atuante como membros do corpo oficial da medicina, acentuou o nível cultural e material da vítima, um indigente, justificando assim tornar-se uma presa fácil nas mãos dos curandeiros. Somemos os qualitativos: ignorância, indigente e curandeiros; características que são reproduzidas nos depoimentos das vítimas, agentes religiosos, advogados e juristas. No entanto, é relevante ressaltar o depoimento do médico-legista - que discursa representando o médico em geral na sociedade ao defender a categoria profissional médica -, que categorizou da seguinte maneira os aspectos positivos a sua profissão e os aspectos negativos ao agente curandeiro (Quadro1).

\begin{tabular}{|c|c|}
\hline \multicolumn{2}{|c|}{ Quadro 1 - Categorias atribuídas ao curandeiro em relação ao médico } \\
\hline CURANDEIRo & MÉDICo \\
Pseudopastores (curandeirices) & Profissionais de saúde \\
Risco e perigo de vidas & Processo saúde-doenca \\
Risco à Saúde Pública & Prática médica científica \\
\hline
\end{tabular}

Interpreto o seguinte. De fato, em geral, os médicos não atribuem aspectos positivos às curandeirices e saberes terapêuticos populares. Defronte a impossibilidade de caracterizá-las por práticas de cura no interior da lógica da complementaridade terapêutica, uma explicação plausível, proveniente da jurisprudência, associa ignorância à questão da remuneração e comportamento de risco, que pode ser expandida à sociedade em geral.

(26) Para menção dos termos atores e palco jurídico, tomei por referência o trabalho de CORREA, M. Morte em familia: representações jurídicas de papéis sexuais. Rio de Janeiro: Grall, 1983. 
Ora, no sistema capitalista em desenvolvimento, faz sentido fazer extinguir práticas de curas que podem se consideradas ultrapassadas quando comparadas ao progresso tecnológico ofertado à sociedade e de modo seguro, científico e oficial, ou que se pretende que assim ocorra. Enfim, faz sentido associar as curandeirices à ignorância, identificando um comportamento de risco social. No entanto, do ângulo antropológico, o sentido das práticas e saberes terapêuticos pode ser ampliado, quando os aspectos sociais do discurso médico sobressaem ao tema de modo ideológico. Verifiquemos, desse olhar, a mesma realidade contada na pesquisa social de Andréa Loyola ${ }^{(27)}$.

Na descrição etnográfica, a autora também aponta um discurso médico que reclama o qualitativo ignorância atribuído aos terapeutas populares. De modo ajustado, a antropóloga circunscreveu a prática médica entre outras práticas de cura, aliás um conjunto de especialistas de cura em Nova Iguaçu (no bairro Santa Rita, Rio de Janeiro). Identificou os profissionais médicos e curandeiros entre os "cuidadores do corpo" e os "cuidadores do espírito". Justificou pela razão na qual o modelo médico é incorporado na formação universitária, pressupondo uma dissimetria atribuída à competência técnica, cuja distância se acentua quanto mais próximo estiverem das práticas dos médicos oficialmente reconhecidos. Concluiu que os médicos adotam atitudes autoritárias frente às representações que os doentes têm do corpo, por suas palavras:

caracterizam os doentes das classes populares por sua "ignorância", desqualificando as representações que estes têm do próprio corpo, da doença e dos princípios de higiênie ... o que mais os diferencia dos outros membros do corpo oficial [os médicos populares] é o fato de conhecerem as práticas médicas populares e de aceitarem as trocas com os especialistas de outros sistemas, seja, por exemplo, recebendo ou encaminhando clientes aos centros de umbanda, seja respeitando o uso de remédios populares. ${ }^{(28)}$

Também pelo ponto de vista das "medicinas tradicionais", Montero (1985) notou que curandeirismo se refere aos conflitos entre as competências da medicina oficial e medicina mágica (umbandista), que perpassam a medicina oficial, justamente por ser uma prática dominante é sempre autoreferente, no sentido de que para ser instituída e exercida se refere a seu próprio exercício e à racionalidade científica que o suporta. ${ }^{(29)}$

(27) LOYOLA, M. A. op. cit.

(28) Id. Ibid., p. 23. Note-se que essa pesquisa social foi realizada antes da implantação do SUS. Certamente que na atualidade as ciências sociais em saúde trabalham nas linhas de pesquisa em educação médica.

(29) MONTERO, P. Da doença à desordem: a magia na umbanda. Rio de Janeiro: Graal, 1985. p. 23. Sobre a dominância e a constituição da medicina universitária enquanto prática hegemônica cf. Cap. I, p.13. 
A antropóloga ainda explorou o assunto das práticas não oficiais de cura, preferindo dialogar a respeito do processo saúde-doença em que as medicinas mágico-religiosas evidenciam por referência a medicina universitária. Percebeu a complementaridade nesse sentido, o da necessidade de definirem para si um espaço legítimo de atuação, deixando o discurso religioso sob dois grupos de doenças, em cuja distinção formal:

visa suprimir ao mesmo tempo o confronto real entre as práticas de cura antagônicas ... e negar a posição subalterna em que a prática mágico-religiosa ocupa em relação à prática médica: as doenças materiais e as doenças espirituais. ${ }^{(30)}$

Porém, os juristas não entendem assim a figura do curandeiro, que se forma historicamente pelas decisões condenatórias ao crime. Os juízes e promotores públicos compreendem características negativas à figura do curandeiro, que reafirma pontos positivos para a prática médica oficial. $\mathrm{O}$ ato de passar substâncias no corpo somente se identifica no ato médico, próprio de um profissional da saúde. Por isso, torna-se perigoso à saúde pública outros praticantes de cura atuarem como médicos, pondo em perigo a saúde da coletividade. No entanto, nesse discurso de proteção inclui a ideologia por detrás dos interesses da corporação profissional médica. Para os juristas, é adequado que o crime de curandeirismo mantenha-se enquanto um crime contra a Saúde Pública, uma vez que organiza as regras sociais, estabelecendo quem deve cuidar e quem deve curar na sociedade. Sobressai desse contexto o poder médico, voltado para intervenção corporal dos indivíduos na sociedade, que se complementa institucionalmente na atuação profissional da medicina ${ }^{(31)}$. Arrisco dizer que o vigor institucional do poder médico no Brasil é proporcional à produção dos aspectos negativos historicamente acumulados sobre os curandeiros na configuração jurídica do termo, que reforça a associação entre ação criminosa e ação curandeira e estabelece, sem contradições, contextos de arbitrariedades a favor da posição social do médico na sociedade.

\section{Do discurso médico do curandeirismo ao campo da saúde}

Com base na teoria de Michel Foucault sobre as relações do poder médico na sociedade exponho em seguida como no discurso médico o curandeirismo fundamenta essas relações de poder. Em um primeiro momento, traduzo em relações de dominação, por dentro do campo jurídico. No segundo momento, discuto o poder médico fora do palco jurídico, na vida cotidiana,

(30) MONTERO, P. Op. cit., p. 110.

(31) Uma referência importante que atualiza o tema biopolitica, confrontar AGAMBEN, G. Homo sacer. o poder soberano e a vida nua. Belo Horizonte: Ed. UFMG, 2002. 
onde se estabelece o saber médico e sua hegemonia de dominação, identificando negativamente as curandeirices em geral e a outros saberes terapêuticos na sociedade.

\subsection{Relações internas do discurso médico sobre curandeirismo}

De que forma está construído mecanismo de poder médico nessa específica relação de dominação? Vimos primeiramente que é no campo jurídico, estruturado de modo permanente, contínuo e selecionado onde se relacionam os atores judiciários (promotores, delegados e juízes) e o corpo de profissionais médicos (médicos-legistas e psiquiatras que elaboram o laudo médico). Em conjunto, historicamente estruturados, reconstróem a categoria curandeirismo. Ao examinarmos os discursos médicos, encontramos mecanismos discursivos que podem ou não ser utilizados em qualquer momento, circunstanciado no mundo da vida. O parecer médico é o discurso mais plausível que inicia a composição da forma do curandeirismo.

Vimos por intermédio do médico-legista dois enunciados que se comple-mentam: a vítima, de baixo nível cultural, torna-se presa fácil para os curandeiros. Ao justificar a competência médica descrevendo a doença (e, por conseguinte, justificando a incompetência do agente curandeiro que interferiu sem tratamento médico), demonstra um grau de instrução e cientificidade, denotando conhecimento e saber nosológico (gangrena).

Fica claro que a partir do uso desses conceitos, como um ato de fala(32), os médicos desencadeiam uma série de enunciados de potência e poder, que se tornam regulares para as autoridades legais. No pensamento de Michel Foucault, esse evento só faz sentido qundo desenvolvido no campo judiciário. O delegado de polícia, os promotores públicos e os juízes baseiam-se no discurso enunciativo do médico para tomarem decisões sobre o ato criminoso do curandeiro.

Assim foi que o delegado de polícia, que fez o relatório final, inicia sua base de argumentações inclinado ao discurso do médico-legista, embora com outras palavras justifica a possível causa que fez com que a vítima procurasse a religião ao invés da verdadeira medicina para "cura de seus males". Ao mesmo tempo em que entende a atuação do profissional médico como sendo autorizada a curar e a competência da religião de produzir a fé, salienta as atitudes religiosas oficiais que atuam no espaço das religiões e que respeitam o campo de competência da medicina oficial: a ignorância categoria depreendida do discurso do médico e que sintetiza o acontecimento enunciativo do curandeirismo empreendido à vítima e ao próprio curandeiro -,

(32) Para a definição de ato de fala confrontar AUSTIN, J. L. How to do things with words. New York: Oxford University Press, 1965. 
encontra-se no discurso do delegado encaminhada ao povo brasileiro que gosta de misticismo, identificando positivamente o que pertence à religião e o que pertence à medicina( ${ }^{(33)}$.

O primeiro promotor de justiça deixou literalmente claro que a acusação estava dirigida à prática de curas em pessoas humildes, embora não tivessem habilitação exigida. Na verdade, o argumento é uma tentativa de identificar ignorância com humildade como características principais produzidas no campo religioso, contrapondo-se à associação entre ignorância, curandeiro, compor-tamento de risco e habitualidade. Dessa forma enunciativa, preservase o que está na lei penal, na lei civil e nos códigos éticos da profissão médica, todos combinados conforme os acontecimentos da vida cotidiana, moldados segundo a lógica dos interessados na formação desta combinação e, também, conforme a realidade de encaixá-los, emoldurá-los, esquadrinhálos aos ideais das leis liberais.

Eles usaram gestos e palavras, prescreveram e ministraram óleo e água benta, persuadindo as pessoas a praticarem processos de cura. Ou seja, esse argumento significa dizer que gestos e palavras fazem parte de atos da religião e prescrever e tocar no corpo (seja somente com óleo) invade a instituição da medicina, o que assim não pertence ao campo religioso.

Penso que o correspondente contrário ao conceito humildade caracterizará o limite da ação religiosa diante da medicina oficial. O saber médico científico, positivo e não religioso, não se adjetiva pela humildade, mas pelo conhecimento adquirido nas ciências médicas. $O$ médico, que conhece a doença e o corpo doente, torna-se impotente diante da ignorância dos agentes religiosos e dos pacientes, cujos desconhecimentos baseiam-se no fato de previligiar a prática religiosa à prática médica, essa enquanto prática de cura oficial atuante no campo científico e com responsabilidade organizada por uma corporação profissional.

\subsection{Relações externas do discurso médico sobre curandeirismo}

No mundo social, em que vigoram os processos judiciais de curandeirismo, a máquina estatal garante os recursos estáticos no tempo e no espaço. Entende-se que, neste relacionamento funcional, o saber médico (universitário) prepondera diretrizes e caracteriza a natureza desta relação como uma relação de dominação sobre outras práticas de cura não médicas, para, num segundo momento, manter o poder e saber médicos hegemônicos na realidade da vida cotidiana.

(33) Essa conotação preconceituosa beira ao racismo. Identifica uma herança no discurso médico de outrora, por exemplo, desde Nina Rodrigues quando associou os rituais religiosos dos negros da Bahia à inferioridade civilizatória em relação à religião hegemônica da Igreja catolica. Confrontar Puttini (Curandeirismo e o campo da saúde no Brasil, cit.). 
Constrói-se, assim, a prática oficial de cura e se cria necessariamente pela categoria curandeirismo a figura criminosa do curandeiro, por onde se concretiza ideologicamente o poder médico, profissional lícito e fora de qualquer cogitação criminosa. Concluo criticamente que o poder médico, originando-se coercitivamente, é de natureza controladora, potencialmente tendencioso a seguir um caminho de controle social, controle da vida social por entre as determinações impostas pelo delegado de polícia, combinado com os demais atores do poder judiciário: entretendo diversos profissionais, estabelecem-se questões de responsabilidade sobre a vida e sua preservação e, portanto, das responsabilidades sobre a morte e seu evitamento. Por conseguinte, tais relações de poder, quando difusas em sociedade, formalizam o controle da vida social também para a manutenção da corporação médica, necessárias, pois distintas no meio social.

Essa distinção entre agentes curandeiros e agentes da medicina oficial propõe explicações diferenciadas. Alerto, entretanto, que tal distinção empreende uma realidade invertida, ideológica no campo da saúde. Entendo que, no decorrer desse trabalho ficou certificada essa ideologia por códigos escritos, seja na forma da lei prescrita, seja na forma de discursos contidos em processos judiciais que se esforçam por enquadrar nas leis. De uma visão mais ampla, porém, podemos encarar tais códigos de interesse, provenientes do corpo profissional médico, dispostos seu poder e distinção social. Essa distinção necessariamente deve de ser preservada a fim de que satisfaça a realidade mesma das instituições médicas, que a mantêm e que por sua vez se dividem entre elas mesmas.

Certamente não se trata de uma ética médica, que seguramente influi na corporação de profissionais médicos. Mas, imprescindível à educação social, onde a sociedade que faz seus regulamentos precise escolher e respeitosamente deliberar sobre caminhos não coercitivos para atingir a saúde da coletividade. Trata-se de valorizar uma bioética social que oriente o sistema de saúde por meio do legítimo controle social no país. Nos espaços do Sistema Único de Saúde (SUS) brasileiro, essa modalidade ética transforma-se em realidade quando voltamos os olhares à institucionalização dos Conselhos locais de Saúde, em que poderiam respeitosamente atuar a comunidade em favor da saúde da coletividade, atualmente uma prerrogativa que possui a corporação médica para ajustar as contas das injustiças sociais no país. Dado na forma de compromisso e responsabilidade social, com vistas à organização da nossa sociedade civil, de que outro modo ou como poderia verdadeiramente expressar-se o poder médico no campo da saúde senão de forma pública e coercitiva?

\section{CONSIDERAÇÕES FINAIS: O PODER MÉDICO NO CAMPO DA SAÚDE}

Com o referencial da teoria arqueológica de Michel Foucault, o presente trabalho contribui para refletir sobre o campo da saúde no Brasil. Apresentei 
os resultados de análise dos discursos médicos e demais atores no palco jurídico a partir do julgamento de um crime de curandeirismo na cidade de Campinas em 1980 com o objetivo de mostrar em quais condições sociais se desenvolve o argumento sobre o curandeirismo em nossa sociedade. $\mathrm{Da}$ atualidade do tema, sobressaiu o vigor negativo empreendido pelo discurso médico sobre práticas curandeiras na sociedade.

Da análise e discussão sobre o poder médico no Brasil, ficou claro que o discurso médico-jurídico reflete também de modo negativo no campo da saúde ao tender identificar as práticas e saberes terapêuticos em geral enquanto práticas curandeiras. Preconiza-se na ação criminosa do curandeirismo uma identidade que personifica a figura universal das curandeirices como ilícitas. Nesses termos, parece insuficiente falar de prática médica no Brasil sem mencionar as relações de poder médico, estabelecidas na forma ideológica e historicamente comprometida com o campo jurídico. Frente ao conjunto das relações de poder, como aqui foram descritas e analisadas as suas peculiaridades nas disposições discursivas, afirmo que as práticas curandeiras têm sido praticadas, certamente porque estão presentes na vida social como uma alternativa à prática médica. Concluo: pensando em uma virada ideológica do conceito de curandeirismo, proponho um desafio maior, que consiste em valorizar as práticas de cura em geral partindo da proposta de se pensar as curandeirices, práticas e saberes terapêuticos populares junto ao Sistema Único de Saúde (SUS), promovendo no campo da saúde um histórico ajuste social no país.

\section{REFERÊNCIAS BIBLIOGRÁFICAS}

AGAMBEN, G. Homo sacer: o poder soberano e a vida nua. Belo Horizonte: Ed. UFMG, 2002.

ALMEIDA FILHO, N. For a general theory of health: preliminary epistemological and anthropological notes. Cadernos de Saúde Pública, Rio de Janeiro, v. 17, n. 4, p. 753-770, 2001.

AUSTIN, J. L. How to do things with words. New York: Oxford University Press, 1965.

BARROS, Nelson Filice de; NUNES, Everardo Duarte. Complementary and alternative medicine in Brazil: one concept, different meanings. Cadernos de Saúde Pública, Rio de Janeiro, v. 22, n. 10, out. 2006.

CAMPOS, J. Q. O hospital, a lei e a ética. São Paulo: São Paulo Ed., 1976.

CORREA, M. Morte em familia: representações jurídicas de papéis sexuais. Rio de Janeiro: Grall, 1983. p. 315.

FOUCAULT, M. A arqueologia do saber. 3. ed. Rio de Janeiro: Forense Universitária, 1987. 
Nascimento da clínica. Tradução de Roberto Machado. Rio de Janeiro: Forense Universitária, Rio de Janeiro, 1987.

As verdades e formas jurídicas: conferências de Michel Foucault na PUC-Rio de 21 a 25 de maio de 1973. Rio de Janeiro: Nau Ed., 1999.

HARING, B. Medicina e moral no século XX. Rio de Janeiro: Ed. Verbo, 1974.

LAUCAS, C. R.; LUZ, M. A estrutura do campo médico homeopático do Rio de Janeiro: reflexões sobre a produção do conhecimento como elemento básico de estruturação institucional sistêmica do campo. Estudos de Saúde Coletiva, n. 178, p. 3-29, 1998.

LÉON, A. C. Ética en medicina. Barcelona: Ed. Científico-Médica, 1973.

LOYOLA, M. A. Médicos e curandeiros: conflito social e saúde. Rio de Janeiro: Difel, 1984.

LUZ, M. Racionalidades médicas e terapêuticas alternativas. Rio de Janeiro: UERJ/IMS, 1993.

MACHADO, R.; Loureiro, A.; Luz, R.; MURICY, K. Danação da norma: medicina social e constituição da psiquiatria no Brasil. Rio de Janeiro: Graal, 1978.

MONTERO, P. Da doença à desordem: a magia na umbanda. Rio de Janeiro: Graal, 1985.

PEIXOTO, I. D. Superstição e crime no Brasil. São Paulo: Revista dos Tribunais, 1980.

POLÍTICA NACIONAL DE PRÁTICAS INTEGRATIVAS E COMPLEMENTARES NO SUS - PNPIC-SUS. Departamento de Atenção Básica, Secretaria de Atenção à Saúde, Ministério da Saúde. Brasília: Ministério da Saúde; 2006.

PUTTINI, Rodolfo Franco. Curandeirismo e o campo da saúde no Brasil. Interface, Botucatu, v. 12, n. 24, mar. 2008.

O poder médico e sua relação com outras práticas de cura. Campinas: Departamento de Medicina Preventiva e Social, Unicamp, 1989. [Relatório de Pesquisa].

QUEIROZ, M. S. Representações sobre saúde e doença: agentes de cura e pacientes no contexto do SUDS. Campinas: Ed. da Unicamp, 1991.

ROSENBAUM, P. Homeopatia: medicina interativa, história lógica da arte de cuidar. Rio de Janeiro: Imago, 2002.

SANTOS FILHO, L. História geral da medicina brasileira. São Paulo: Hucitec; Edusp, 1977.

SCHRITZMEYER, A. L. P. Sortilégio de saberes: curandeiros e juízes nos tribunais brasileiros (1900-1990). São Paulo: IBCCrim, 2004. 


\section{Revistas Jurídicas consultadas}

JULGADOS DO TRIBUNAL DE ALÇADA CRIMINAL DE SÃO PAULO (JUTACRIM), São Paulo. Revista Oficial do Tribunal de Alçada Criminal do Estado de São Paulo, Lex Editora, publicação trimestral.

REVISTA TRIBUNAL DE JURISPRUDÊNCIA (RTJ). Organizado pela Divisão Jurisprudência, Editora Supremo Tribunal Federal.

REVISTA DOS TRIBUNAIS (RT), São Paulo, Editora Revista dos Tribunais. JURISPRUDÊNCIA DO SUPREMO TRIBUNAL FEDERAL (LEX JSTF). São Paulo, Lex Editora.

REVISTA DE JURISPRUDÊNCIA DO TRIBUNAL DE JUSTIÇA DO ESTADO DE SÃO PAULO (RJTJ). São Paulo.

REVISTA OFICIAL DO TRIBUNAL DO ESTADO DE SÃO PAULO, Lex Editora. REVISTA FORENSE (RF). São Paulo, Lex Editora. 